\title{
Patient Perspectives on a Digital Mobile Health Application for RA
}

\author{
Simran Chahal' \\ Norma Biln (D) ${ }^{\prime}$ \\ Bruce Clarke ${ }^{2}$ \\ 'Augurex Life Sciences Corp., Vancouver, \\ British Columbia, Canada; ${ }^{2}$ B2 \\ Consulting, Kelowna, British Columbia, \\ Canada
}

Background: Emerging evidence suggests that patients are increasingly willing to use digital mobile health applications for rheumatoid arthritis (RA apps). The development and diffusion of RA apps open the possibility of improved management of the disease and better physician-patient interactions. However, adoption rates among apps have been lower than hoped, and research shows that many available RA apps lack key features. There is little research exploring patient preferences for RA apps or patients' habits and preferences for app payment, which are likely key factors affecting adoption of this technology. This study seeks to understand characteristics of RA patients who have adopted RA apps, their preferences for app features, and their willingness to pay for, and experiences with app payment.

Methods: Data for this study come from a 33-question online survey of patients with RA in Canada and the United States $(\mathrm{N}=30)$. Information on demographics, diagnosis and management of RA, current use and desired features of RA apps, and prior experience with and willingness to pay for an app was collected. Descriptive statistics are reported, and bivariate analyses (chi-square, point-biserial correlation, and ANOVA) were performed to understand relationships between variables.

Results: Respondents showed a clear preference for certain app features, namely symptom tracking, scheduling appointments, and reminders. Physician recommendation for an app and patient tracking of symptoms with an app were significantly related to patient adoption of an RA app. Years since diagnosis with RA, physician recommendation for an RA app, and current use of a non-RA health tracking app were significantly related to patients' willingness to pay a subscription for an RA app.

Conclusion: RA patients appear to prefer task support features in an RA app, notably symptom tracking, appointment scheduling, and reminders, over other features such as those related to dialogue support and social support. The choice of whether an RA app will be free or based on a subscription, pay-per-service, or one-time purchase model may also play a role in eventual adoption. Similarly, physician recommendation appears to influence patients' decision to use an RA app as well as their willingness to pay a subscription for an app.

Keywords: digital health application, adoption, willingness to pay

\section{Background}

Evidence is emerging showing patients' willingness to use mobile applications for rheumatoid arthritis (RA apps) to better manage this chronic disease. One study, for example, examining RA patients' preferences for use and functionality in an RA app through a survey of 176 patients with chronic rheumatic diseases, found that $68 \%$ believed that using medical apps could be beneficial for their own health, and
Correspondence: Simran Chaha

Augurex Life Sciences, Suite 220 - 887

Great Northern Way, Vancouver, British

Columbia, V5T 4T5, Canada

$\mathrm{Tel}+$ I 604-637-3280

Email schahal@augurex.com 
a similar number (67\%) would regularly enter data using an app. ${ }^{1}$ In a UK-based trial, study participants confirmed both the acceptability and feasibility of an RA app, citing both ease of use and the benefits of a graphical display of symptom severity over time. ${ }^{2}$

The development and diffusion of RA apps also open the possibility of improved physician-patient interactions. A randomized clinical trial of an RA app found no statistically significant differences in patient satisfaction or disease activity among those who used an RA app to coordinate care compared to those not using an app. ${ }^{3}$ In a study testing the feasibility of a self-assessment system for RA patients using a smartphone application in nine patients over a three-month period, researchers found that the disease activity measured by the app correlated well with the patients' actual disease activity, and could therefore be a useful tool for both patients and providers in monitoring disease progression. ${ }^{4}$ The potential benefits of RA apps are even greater if patient-reported outcomes (PROs) collected through an app can be incorporated into clinical workflows. ${ }^{5}$ A study of 185 RA patients, which compared paper-based collection of PROs to appbased collection and concluded that apps for RA are effective modalities for the collection of PROs, suggests such benefits are, indeed, possible. ${ }^{6}$

However, despite both the potential and demonstrated benefits of these technologies, adoption rates of RA apps among patients have been lower than hoped, and the market for RA apps has been described as in its infancy. ${ }^{7}$ For example, study of e-health used among RA patients (ie, internet, mobile apps, and connected devices) found a small number of patients using an RA app. ${ }^{8}$ Of 575 respondents, only $8 \%$ used an RA app for clinical followup, and $2 \%$ used an RA app for medication reminders.

Increasing the adoption rates of RA apps means overcoming important barriers. Patients and providers require easy-to-use and intuitive systems. Payers demand solutions that demonstrate value. Clinicians appropriately insist on precision in data. Understanding these desires and unmet needs, as well as the shortcomings in current RA apps, therefore, is key to ensuring the refinement, diffusion, and eventual adoption of these technologies.

A growing literature has critically examined available RA apps. Mollard identifies two broad categories of RA apps. ${ }^{9}$ Self-management apps include those that offer RA disease education, lifestyle education and monitoring, community connection-based apps, and those that connect users to rheumatologist providers. Self-monitoring RA apps are those that allow patients to record and monitor activity, such as medication management and pain management. In principle, a single app could provide both types of functionalities; however, in practice, offerings tend to be more restricted. In their systematic review, Luo et al found that among the 20 apps identified for RA on the iTunes and Google Play App Stores, most did not provide a comprehensive experience for patients. Half offered symptom tracking only, $20 \%$ only provided information about RA, and less than half provided way for patients to contact health care providers or link to an online community. ${ }^{3}$ Similarly, Bhattarai et al observed that few RA apps offered a comprehensive pain selfmanagement approach that incorporated evidence-based strategies. ${ }^{10}$ Notably missing were mechanisms for symptom monitoring and symptom management-both key factors of self-management.

One possible reason for the development of RA apps with sub-optimal features is the app development process itself. ${ }^{11}$ In a systematic review covering 32 articles on apps for the self-management of rheumatic and musculoskeletal diseases, of which 11 focused on RA, Nejm et al found that physicians were rarely involved in app evaluation, and patient involvement was largely indirect (e.g, by developers monitoring patient adherence to apps). The result has been apps where references are unavailable or out of date. Grainger et al compared existing apps' features to rheumatoid arthritis management recommendations. ${ }^{12}$ Of the 19 apps included in the study, the vast majority did not meet these criteria, and the authors note a lack of highquality apps for longitudinal assessment of RA. A better knowledge among developers of factors such as design improvements and clear instructions may assist patients in using apps effectively. ${ }^{10}$

Geuens et al argue that designing RA-specific mobile apps with persuasive principles may more effectively ensure behavioural change among patients. ${ }^{13}$ Categories of persuasive principles that can be integrated into mobile apps, for example, include task support (logging, goal setting), dialogue support (reminders, suggestions), system credibility (third-party endorsements, surface credibility), and social support (social interaction, social learning). In their study of apps available in the Google Play, Apple App Store, and Windows Phone Store, the authors found that fewer than six of 38 persuasive principles were used in each app. The most common persuasive principles were system credibility, followed by task support, dialog support, and social support. They concluded that apps would benefit from adding social 
support techniques. Likewise, a review of RA apps available in the German Google Play and App Store found apps of mixed quality. ${ }^{14}$ The authors use the mobile application rating scale, ${ }^{15}$ which assesses apps along five domains (engagement, functionality, aesthetics, information, and subjective quality) to assess $16 \mathrm{RA}$ apps. The authors identified the use of supporting clinical studies, validated questionnaires, and involvement of academic developers as factors that could lead to an improvement in future RA apps.

Another set of barriers to adoption revolves around features of the RA app itself and patient-specific characteristics. A pilot study of a mobile app with hand optical imaging capabilities for patients with RA revealed several such barriers to use, citing patients' frustration with the technology, satisfaction with another current self-management system, and difficulty in using the technology because of RA as reasons why they would not use the app. ${ }^{16}$ Another study of RA app use found that older age ( $\geq 65$ years) and low baseline clinical disease acuity were statistically significant predictors of adherence to the app. ${ }^{17}$ E-health literacy may also play a role: patients with higher e-health literacy are more likely to believe that apps are helpful compared to their lower e-health literate counterparts. ${ }^{1}$

Overall, while the literature has catalogued the types of RA apps and their shortcomings, both in terms of initial design and features, key factors regarding RA app adoption remain understudied or unknown. First, there is little in the literature specifically describing characteristics of RA patients likely to adopt RA apps. Second, it remains unclear, despite several reviews of RA app offerings, the specifics of patient preferences for RA app functionality. Finally, we are unaware of any study specific to RA patients that examined patients' habits and preferences for app payment, ie, if they were willing to pay for an RA app and, if so, their preferences for doing so. Attempts to increase RA app diffusion will likely have to address these factors.

We undertook this study to understand better the characteristics of RA patients who have adopted RA apps, as well as RA patients' preferences (whether using an app or not) for features included in an RA app. We also sought to explore issues around RA patients' willingness to pay for, and experience with, app payment.

\section{Methods}

Data for this study come from a 33-question survey of patients with RA in Canada and the United States. Inclusion criteria were diagnosed with RA, between 18 and 60 years of age, use a smart device, and had prior experience using apps to manage their health. The survey was conducted online over a one-week period in April 2018. A total of 30 respondents who met the inclusion criteria completed the survey.

The survey instrument included four categories of questions: demographics (eg, sex, age); diagnosis and management of RA (eg, years since diagnosed, usual source of care for RA); current use and desired features of RA apps (eg, track symptoms, schedule appointments, receive reminders for lab results); and prior experience with and willingness to pay for an app (eg, ever paid a subscription to an app). Respondents were presented with a mock-up and list of possible functionalities for an RA app as part of the online survey.

Data were analyzed using Microsoft Excel with the XLMiner Analysis ToolPak. ${ }^{18}$ Raw data from the online data collection tool were recoded to appropriate categories. For each variable, descriptive statistics (count and percentage, mean, standard deviation) were calculated.

To explore the relationship between use of an RA app, willingness to pay for an app, and other variables, we performed a series of significance tests. For comparisons of categorical variables, we used chi-square tests. For the comparison between use of an RA app (dichotomous variable) and number of years since diagnosed (continuous variable), we calculated a point-biserial correlation. For the comparison between willingness to pay (categorical) and number of years since diagnosis (continuous variable), we performed a one-way ANOVA.

\section{Results}

Tables 1 and 2 show the sex, age, and diagnosis and management of RA results. Nearly three-quarters of respondents (73\%) were male. Two-thirds were between the ages of 18 and 44 , with the remaining respondents between the ages of $45-54(20 \%)$ or $55-60(13 \%)$.

With respect to the diagnosis and management of RA, respondents reported an average of nearly seven years

Table I Sex and Age of Respondents ( $=30)$

\begin{tabular}{|l|l|}
\hline Variable & Value (Percent) \\
\hline Sex & $\bullet$ Male (73\%) \\
& $\bullet$ Female (27\%) \\
\hline Age (years) & $\bullet 18-34(33 \%)$ \\
& $\bullet 35-44(33 \%)$ \\
& $\bullet 45-54(20 \%)$ \\
& $\bullet 55-60(13 \%)$ \\
\hline
\end{tabular}


Table 2 Diagnosis and Management of RA

\begin{tabular}{|c|c|c|}
\hline Variable & Value (Percent) & Mean (SD) \\
\hline $\begin{array}{l}\text { How long since diagnosed } \\
\text { with RA (years) }\end{array}$ & - & $6.97(7.56)$ \\
\hline $\begin{array}{l}\text { Who made the initial } \\
\text { diagnosis }\end{array}$ & $\begin{array}{l}\text { - Primary care specia- } \\
\text { list/GP }(40 \%) \\
\text { - Rheumatologist } \\
(60 \%)\end{array}$ & - \\
\hline $\begin{array}{l}\text { Time from first symptoms } \\
\text { to diagnosis (months) }\end{array}$ & - & $5.85(4.31)$ \\
\hline $\begin{array}{l}\text { Time from first visit with } \\
\text { GP to rheumatologist } \\
\text { appointment (months) }\end{array}$ & - & $3.47(3.15)$ \\
\hline $\begin{array}{l}\text { Who is responsible for } \\
\text { follow up care }\end{array}$ & $\begin{array}{l}\text { - Rheumatologist } \\
(43 \%) \\
\text { - Primary care physi- } \\
\text { cian/GP (33\%) } \\
\text { - Primary care physi- } \\
\text { cian/GP and rheuma- } \\
\text { tologist equally (23\%) }\end{array}$ & - \\
\hline
\end{tabular}

since they were first diagnosed with RA, with a majority $(60 \%)$ having the initial diagnosis made by a rheumatologist. Time from first symptoms to diagnosis averaged nearly half a year (5.85 months), while time from first visit with GP to rheumatologist appointment roughly three-and-a-half months (3.47). Responsibility for followup care fell among rheumatologists (43\%), primary care physician (33\%), or both (23\%).

Respondents were asked to report on their usage of an RA app (Table 3). The respondents were nearly evenly split between those who were currently using an app to manage their RA (53\%) and those who were not (47\%). All respondents were likely $(40 \%)$ or very likely $(60 \%)$ to use a specific app if it were recommended by a physician.

Among those who did use an RA app, no single modality dominated. The most common way for finding and selecting the app was via physician recommendation (20\%). This was followed by online research (17\%); peer recommendation or website (each 13\%); advertisement (7\%); and pharmaceutical company or insurer (each 3\%). No response was given to this question by $13 \%$ of respondents.

To understand RA patients' preferences for functionalities in an RA app, respondents were presented with images of a mock app screen and a list of features. Respondents were asked first to rate each item's usefulness on a scale of 1 to 5 ,
Table 3 Respondents Who Use Apps to Manage RA

\begin{tabular}{|l|l|}
\hline Variable & Value (Percent) \\
\hline $\begin{array}{l}\text { Currently using app to manage } \\
\text { RA }\end{array}$ & $\begin{array}{l}\text { Yes (53\%) } \\
\text { No (46\%) }\end{array}$ \\
\hline $\begin{array}{l}\text { If physician recommended app, } \\
\text { how likely would you be to use } \\
\text { it }\end{array}$ & $\begin{array}{l}\text { Very likely (60\%) } \\
\text { Likely (40\%) } \\
\text { Not very likely (0\%) } \\
\text { Not sure (0\%) }\end{array}$ \\
\hline $\begin{array}{l}\text { Among those using an app: How } \\
\text { did you find and choose an app }\end{array}$ & $\begin{array}{l}\text { Online research (I7\%), Physician } \\
\text { recommendation (20\%), App } \\
\text { store search (I0\%), Peer } \\
\text { recommendation (13\%), } \\
\text { Pharmaceutical company (3\%), } \\
\text { Insurer (3\%), Advertisement (7\%), } \\
\text { Website (I3\%).No response } \\
\text { (I3\%) }\end{array}$ \\
\hline
\end{tabular}

with 5 indicating the most useful, and second to rank three of the features as their first-, second-, or third-top preferred feature. Figure 1 shows these results.

Respondents showed a clear preference for certain RA app features, with 25 (83\%) identifying "track symptoms" as their first (18), second (6) or third (1) preferred choice. This was followed by "schedule appointments and retrieve reminders," which was selected as a preferred feature for 18 respondents. Both "lab results" and "track health" were identified by as preferred features for 11 respondents. "Track medication and symptoms for RA" was selected by a further 8 respondents, and the remaining features were selected by 5 or fewer respondents.

Respondents' rating of each feature's usefulness generally mirrored these results. "Track symptoms" (4.60) and "schedule appointments and receive reminders" (4.43), for example, received the highest average ratings. Interestingly, some items, such as "identify changes in symptoms and alert the patient when to visit the physician," were rated relatively useful but only selected by a small number of respondents as their first-, second-, or third-top choice.

Finally, respondents were asked "Based on the description, is there any feature missing that you think might be helpful?" All but one respondent (97\%) responded "no".

The data show several statistically significant relationships among variables (Table 4). Use of an RA app was significantly related to number of years since diagnosed with RA, whether respondents tracked symptoms as part 


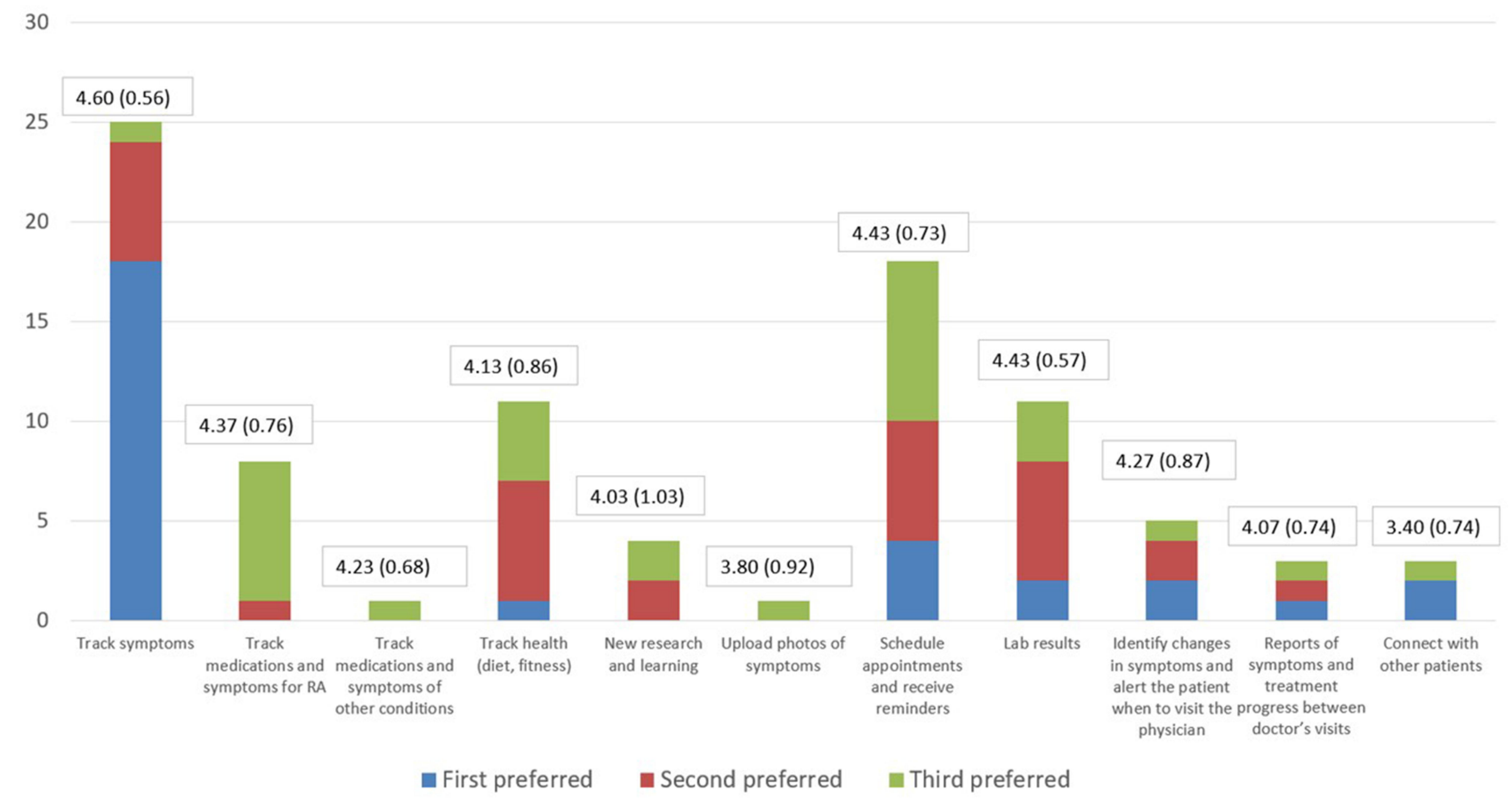

Figure I $\quad$ First preferred $\$ Second preferred $\square$ Third preferred.

of their current regimen, and whether their physician had ever recommended any mobile apps or online clinical assessment tools to help manage RA.

Similarly, willingness to pay a subscription for an RA app was significantly related to number of years since diagnosed with RA, how likely a respondent reported they would be to use an app if recommended by their physician, and whether respondents were currently using mobile apps or devices to track other health outcomes, such as fitness or diet.

Interestingly, neither sex, age category, nor responses to questions regarding the management of RA, including type of physician responsible for care, frequency of visits to a GP or rheumatologist, or frequency of blood work or imaging, were significantly related to use of an RA app or willingness to pay for a subscription for one.

Table 5 shows the results of questions related to willingness to pay for an app. Respondents were split roughly equally among those who would be willing (33\%), would not be willing $(30 \%)$, and were unsure if they would be willing to pay a subscription. The majority had made a one-time payment for an app (70\%), an in-app purchase (53\%), and collected points or incentives from an app that could be redeemed (63\%). Only 30\% had ever paid a subscription to an app. If a cost were associated with an app, $50 \%$ indicated that making a one-time payment would be their first choice, followed by paying only for features that they would use $(37 \%)$ and paying for a subscription (13\%).

\section{Discussion}

We sought in this study to understand better several aspects of RA app use, namely the characteristics of patients who have adopted RA apps, their preferences for features included in an RA app, and issues around willingness to pay and experience with app payment.

Regarding the characteristics of RA app adopters versus non-adopters, adoption of an RA app appears related to whether patients track their symptoms. For example, among those who do not track their symptoms, most (66\%) have not adopted an RA app. Likewise, among those who do track, 78\% have adopted an RA app, suggesting that symptom tracking is facilitated by presence of an RA app. Patients' use of mobile apps to track other, non-RA health outcomes is also related to their willingness to pay for a subscription to an RA app, raising the possibility that familiarity and use of any health-related app increases perceived value and, therefore, willingness to pay for an RA app.

Several of the results point to the importance of a physician's recommendation in the patients' app use. 
Table 4 Relationships Among Selected Variables

\begin{tabular}{|c|c|c|c|}
\hline Question & $\begin{array}{l}\text { Distribution (Percent) or } \\
\text { Mean (Standard Deviation) }\end{array}$ & $\begin{array}{l}\text { Are You Currently } \\
\text { Using Any Apps to } \\
\text { Manage Your RA? } \\
\text { (Yes, No) }\end{array}$ & $\begin{array}{c}\text { If a Mobile App That Met Your Needs } \\
\text { in the Monitoring and Management } \\
\text { of Your RA, Would You Be Willing to } \\
\text { Pay a Subscription? (Yes, No, } \\
\text { Unsure) }\end{array}$ \\
\hline Age & $\begin{array}{l}\text { I8-34 (33\%), 35-44 (33\%), 45-54 } \\
(20 \%), 55-60 \text { (I3\%) }\end{array}$ & n.s. & n.s. \\
\hline Sex & $\begin{array}{l}\text { Male }(73 \%) \\
\text { Female }(27 \%)\end{array}$ & n.s. & n.s. \\
\hline $\begin{array}{l}\text { How many years ago were you } \\
\text { diagnosed with RA? }\end{array}$ & $6.97(7.57)$ & n.s. ${ }^{a}$ & $\mathrm{P}<0.0 \mathrm{I}^{\mathrm{b}}$ \\
\hline Type of physician responsible for care & $\begin{array}{l}\text { PCP/GP (33\%) } \\
\text { Rheumatologist (43\%) } \\
\text { Both }(23 \%)\end{array}$ & n.s. & n.s. \\
\hline How often visit GP for RA treatment & $\begin{array}{l}0-2 \text { times per year ( } 43 \%) \\
3 \text { or more times per year (57\%) }\end{array}$ & n.s. & n.s. \\
\hline $\begin{array}{l}\text { How often visit Rheumatologist for } \\
\text { RA treatment }\end{array}$ & $\begin{array}{l}0-2 \text { times per year }(50 \%) \\
3 \text { or more times per year (50\%) }\end{array}$ & n.s. & n.s. \\
\hline $\begin{array}{l}\text { How often do you have blood work } \\
\text { done to track the progression of } \\
\text { your RA? }\end{array}$ & $\begin{array}{l}0-2 \text { times per year }(50 \%) \\
3 \text { or more times per year (50\%) }\end{array}$ & n.s. & n.s. \\
\hline $\begin{array}{l}\text { How often do you have imaging done } \\
\text { (X-rays, MRIs, ultrasound) to track } \\
\text { the progression of your RA? }\end{array}$ & $\begin{array}{l}\text { Once every } 2 \text { years or more } \\
(57 \%) \\
\text { Once every } 3 \text { years or less ( } 43 \%)\end{array}$ & n.s. & n.s. \\
\hline $\begin{array}{l}\text { As part of your treatment regimen, } \\
\text { do you currently track your } \\
\text { symptoms }\end{array}$ & $\begin{array}{l}\text { Yes }(70 \%) \\
\text { No }(30 \%)\end{array}$ & $\mathrm{P}<0.05$ & n.s. \\
\hline $\begin{array}{l}\text { Has your physician ever } \\
\text { recommended any mobile apps or } \\
\text { online clinical assessment tools to } \\
\text { help manage your RA? }\end{array}$ & $\begin{array}{l}\text { Yes }(66 \%) \\
\text { No }(33 \%)\end{array}$ & $\mathrm{P}<0.01$ & n.s. \\
\hline $\begin{array}{l}\text { If your physician recommended an } \\
\text { app to you, how likely would you be } \\
\text { to use it? }\end{array}$ & $\begin{array}{l}\text { Very likely }(60 \%) \text {, Likely }(40 \%) \\
\text { Not very likely }(0 \%) \text {, Not sure } \\
(0 \%)\end{array}$ & n.s. & $\mathrm{P}<0.05$ \\
\hline $\begin{array}{l}\text { Are you currently using any mobile } \\
\text { apps or devices to track other health } \\
\text { outcomes, such as fitness or diet? }\end{array}$ & $\begin{array}{l}\text { Yes }(66 \%) \\
\text { No }(33 \%)\end{array}$ & n.s. & n.s. \\
\hline $\begin{array}{l}\text { Are you currently using any apps to } \\
\text { manage your RA? }\end{array}$ & $\begin{array}{l}\text { Yes }(47 \%) \\
\text { No }(53 \%)\end{array}$ & - & n.s. \\
\hline $\begin{array}{l}\text { Are you currently using any mobile } \\
\text { apps or devices to track other health } \\
\text { outcomes, such as fitness or diet? }\end{array}$ & $\begin{array}{l}\text { Yes }(66 \%) \\
\text { No }(33 \%)\end{array}$ & n.s. & $\mathrm{P}<0.05$ \\
\hline
\end{tabular}

Notes: All correlations determined with Chi-square tests unless otherwise noted; ${ }^{\text {a }}$ Point-biserial correlation $=0.034 ;{ }^{b}$ ANOVA, F-statistic $=12.59$, DFI $=1$, DF2 $=58$. Abbreviation: n.s., not significant. 
Table 5 Willingness to Pay

\begin{tabular}{|c|c|}
\hline Variable & Value (Percent) \\
\hline $\begin{array}{l}\text { If a mobile app met your needs, } \\
\text { would you be willing to pay } \\
\text { a subscription }\end{array}$ & $\begin{array}{l}\text { - } \quad \text { Yes }(33 \%) \\
\text { - } \quad \text { No }(30 \%) \\
\text { - Unsure }(37 \%)\end{array}$ \\
\hline Ever paid a subscription to an app & $\begin{array}{l}\text { - } \text { Yes }(30 \%) \\
\text { - } \quad \text { No }(70 \%)\end{array}$ \\
\hline $\begin{array}{l}\text { Ever made a one-time payment } \\
\text { for an app }\end{array}$ & $\begin{array}{l}\text { - } \quad \text { Yes }(70 \%) \\
\text { - } N o(30 \%)\end{array}$ \\
\hline Ever made an in-app purchase & $\begin{array}{l}\text { - } \text { Yes }(53 \%) \\
\text { - } \quad \text { No }(47 \%)\end{array}$ \\
\hline $\begin{array}{l}\text { Ever collected points or } \\
\text { incentives from an app that could } \\
\text { be redeemed }\end{array}$ & $\begin{array}{l}\text { - } \quad \text { Yes }(63 \%) \\
\text { - } \quad \text { No }(37 \%)\end{array}$ \\
\hline $\begin{array}{l}\text { How would you prefer to pay if } \\
\text { a cost were associated with an } \\
\text { app }\end{array}$ & $\begin{array}{l}\text { Percent reporting option as } \\
\text { their first, second, and third } \\
\text { choice: } \\
\text { - Pay for a subscription } \\
(13 \%, 27 \%, 60 \%) \\
\text { - Make a one-time payment } \\
\text { (50\%, } 40 \%, 10 \%) \\
\text { Pay for features I will use } \\
\text { (37\%, 33\%, 30\%) }\end{array}$ \\
\hline
\end{tabular}

First, there is a highly statistically significant relationship between a physician every having recommended an RA app and patients' use of an RA app. Second, patients' likelihood of using a physician-recommended app is significantly related to their willingness to pay for an app. Finally, the most cited way for patients to find and select an app was via physician recommendation. These results suggest that a physician recommendation influences not only the decision to find, select, and adopt an RA app, but also their willingness to pay a subscription for an RA app.

The relationship between willingness to pay a for a subscription and RA app adoption was highly statistically significant $(\mathrm{p}<0.01)$. Those willing to pay had been diagnosed with RA more recently (4.9 years ago) than those reporting they were unwilling ( 8.2 years ago) or unsure (9.5 years ago) of their willingness to pay. It is unlikely this an age-related phenomenon, ie, of older respondents being unwilling to pay a subscription, since no statistically significant relationship between willingness to pay and respondent age was found. One possibility may be related to stability of disease management: unlike the relatively newly diagnosed, those diagnosed many years ago may simply be more accustomed or satisfied with their management of RA and believe that the additional cost of a RA app subscription does not merit the perceived benefits.

With respect to patient preferences for features in an RA app, the results offer some direction for future apps. First, the clear preference for four of them-track symptoms, schedule appointments/receive reminders, track health, and lab results - speaks to the desire for RA apps that assist with specific disease management tasks. Second, consistent with the application of persuasive design principles, these findings support task support and dialogue support. ${ }^{13}$ Interestingly, the one proposed feature that would be categorized as social support - "connect with other patients" - was among the least-frequently selected as a top choice and received the lowest average score for usefulness.

The results related to willingness to pay suggest some interesting trends. Even though a majority of patients had made a one-time payment for an app or an in-app purchase, only a minority (30\%) were willing to pay a subscription for an RA app. If there were a cost for an app, patients would rather make a one-time payment or pay for services that they would use-important considerations for increasing adoption and use. Moreover, the statistically significant link between physician recommendation of an app and patient willingness to pay a subscription suggest that, should developers choose this business model, the role of the physician in influencing patients' purchasing decisions will have to be carefully considered.

The primary limitation of the study is its small sample size, which prevented more robust multivariate analyses. For example, although a logistic regression with RA app adoption as a dichotomous dependent variable might reveal the direction and magnitude of the independent relationships between that variable and others in the dataset, a model with three independent variables would require an $\mathrm{n}$ of at least $250 .{ }^{19}$ The small sample size of this study limits the ability to extrapolate to a larger population.

A second challenge stems from the nature of RA apps themselves. This study focused on the experiences and preferences of patients. However, optimal management of RA requires the interaction of multiple stakeholders, including patients, physicians, and other care providers. Each may have their own preferences for how an app should be designed and what it should include. While the results in this study highlight patients' preferences for app features, 
non-patients may value these particular features differently or, perhaps, desire a different set of features entirely. Some of this tension might be seen in the discrepancy found here between patients' perceived usefulness of a feature and their (non-) selection of it as a first-, second-, or third-top choice. Cases where features were ranked highly useful but not selected as a top choice might reflect patients' sense of its usefulness to other stakeholders (ie, physician or caregiver) rather than their own desire to have it as part of the app. Future studies may benefit from examining additional stakeholders' preferences and experiences.

Despite these limitations, the current study brings to light some unique findings. First, patients appear to prefer task support features in an app, notably symptom tracking, appointment scheduling, and reminders, over other features such as those related to dialogue support and social support. While apps that offer a full patient experience may require additional features more useful to other stakeholders, including physicians and caregivers, developers will have to consider these patient preferences.

A second set of findings also related to adoption and use are those around the business model and app payment. The literature to date has focused primarily on clinical, usability, and other development-related factors of RA apps. However, as these data suggest, the choice of whether and RA app will be free or based on a subscription, pay-per-service, or one-time purchase model may also play a role in eventual adoption and, therefore, merit attention in future research.

Finally, is the influence of the physician on patient behavior, which was revealed in patients' decisions to use and willingness to pay for an RA app. That "physician recommendation" was cited as the most common way for patients to find and select an app also speaks to this influence. These findings support assertions that physicians should be involved early in the app development process, not only to ensure clinical accuracy and usability, but also to encourage eventual adoption and use.

\section{Abbreviations}

RA, rheumatoid arthritis; RA app, digital health application for rheumatoid arthritis; PCP, primary care provider.

\section{Data Sharing Statement}

Data sharing is not applicable to this article as no datasets were generated or analysed during the current study.

\section{Acknowledgments}

The authors wish to acknowledge the editorial assistance of Jonathan D. Agnew, PhD, MBA in preparation of this manuscript.

\section{Author Contributions}

All authors contributed to data analysis, drafting or revising the article, have agreed on the journal to which the article will be submitted, gave final approval of the version to be published, and agree to be accountable for all aspects of the work.

\section{Funding}

This project was funded by the National Research Council Industry Research Assistance Program (NRC-IRAP).

\section{Disclosure}

Simran Chahal and Norma Biln are employees of Augurex Life Sciences. Simran Chahal reports grants from National Research Council - Industry Research Assistance Program (NRC-IRAP) during the conduct of the study; Norma Biln reports grants from NRC-IRAP, during the conduct of the study. Bruce Clarke has no competing interests to declare.

\section{References}

1. Knitza J, Simon D, Lambrecht A, et al. Mobile health in rheumatology: a patient survey study exploring usage, preferences, barriers and ehealth literacy. JMIR Mhealth Uhealth. 2020. doi:10.2196/ preprints. 19661

2. Austin L, Sharp CA, van der Veer SN, et al. Providing 'the bigger picture': benefits and feasibility of integrating remote monitoring from smartphones into the electronic health record. Rheumatology. 2020;59 (2):367-378. doi:10.1093/rheumatology/kez207

3. Luo D, Wang P, Lu F, Elias J, Sparks JA, Lee YC. Mobile apps for individuals with rheumatoid arthritis. J Clin Rheumatol. 2019;25 (3):133-141. doi:10.1097/RHU.0000000000000800

4. Nishiguchi S, Ito H, Yamada M, Yoshitomi H, Furu M. Self-assessment of rheumatoid arthritis disease activity using a smartphone application. Development and 3-month feasibility study pervasive games for elderly view project hospital management view project. Methods Inf Med. 2016;55:65-69. doi:10.3414/ME14-01-0106

5. Gandrup J, Yazdany J. Using health information technology to support use of patient-reported outcomes in rheumatology. Rheum Dis Clin North Am. 2019;45(2):257-273. doi:10.1016/j.rdc.2019.01.007

6. Epis OM, Casu C, Belloli L, et al. Pixel or paper? Validation of a mobile technology for collecting patient-reported outcomes in rheumatoid arthritis. JMIR Res Protoc. 2016;5(4):e219. doi:10.2196/ resprot.5631

7. Mollard E, Michaud K. Mobile apps for rheumatoid arthritis: opportunities and challenges. Rheum Dis Clin. 2019;45:197-209. doi:10.1016/j.rdc.2019.01.011

8. Magnol M, Eleonore B, Claire R, et al. Use of eHealth by patients with rheumatoid arthritis: observational, cross-sectional, multicenter study. J Med Internet Res. 2021;23:e19998. doi:10.2196/19998

9. Mollard E, Michaud K. Self-management of rheumatoid arthritis: mobile applications. Curr Rheumatol Rep. 2021;23(1). doi:10.1007/ s11926-020-00968-7 
10. Bhattarai P, Newton-John T, Phillips JL. Quality and usability of arthritic pain self-management apps for older adults: a systematic review. Pain Med. 2018;19:471-484. doi:10.1093/pm/pnx090

11. Najm A, Gossec L, Weill C, Benoist D, Berenbaum F, Nikiphorou E. Mobile health apps for self-management of rheumatic and musculoskeletal diseases: systematic literature review. JMIR Mhealth Uhealth. 2019;7:e14730. doi:10.2196/14730

12. Grainger R, Townsley H, White B, Langlotz T, Taylor WJ. Apps for people with rheumatoid arthritis to monitor their disease activity: a review of apps for best practice and quality. JMIR Mhealth Uhealth. 2017;5(2):e6956. doi:10.2196/mhealth.6956

13. Geuens J, Thijs M, Swinnen W, et al. A review of persuasive principles in mobile apps for chronic arthritis patients: opportunities for improvement. JMIR Mhealth Uhealth. 2016;4:e118. doi:10.2196/ mhealth. 6286

14. Knitza J, Tascilar K, Messner EM, et al. German mobile apps in rheumatology: review and analysis using the mobile application rating scale (MARS). JMIR Mhealth Uhealth. 2019;7(8):e14991. doi:10.2196/14991
15. Stoyanov SR, Hides L, Kavanagh DJ, Zelenko O, Tjondronegoro D, Mani M. Mobile app rating scale: a new tool for assessing the quality of health mobile apps. JMIR Mhealth Uhealth. 2015;3(1):e3422. doi:10.2196/mhealth.3422

16. Mollard E, Michaud K. A mobile app with optical imaging for the self-management of hand rheumatoid arthritis: pilot study. JMIR Mhealth Uhealth. 2018;6:e12221. doi:10.2196/12221

17. Colls J, Lee YC, Xu C, et al. Concise report patient adherence with a smartphone app for patient-reported outcomes in rheumatoid arthritis. Rheumatology. 2021;60:108-112. doi:10.1093/rheumatology/keaa202

18. Frontline Systems, Inc.XLMiner Analysis ToolPak (Version 1.0.0.0) [Application software]; 2014. Available from: https://appsource. microsoft.com/en-us/product/office/WA104379190?tab=Overview. Accessed March 4, 2021.

19. Bujang MA, Sa'at N, Bakar TM. Sample size guidelines for logistic regression from observational studies with large population: emphasis on the accuracy between statistics and parameters based on real life clinical data. Malays J Med Sci. 2018;25(4):122-130. doi:10.21315/mjms2018.25.4.12
Open Access Rheumatology: Research and Reviews

\section{Publish your work in this journal}

Open Access Rheumatology Research and Reviews is an international, peer-reviewed, open access journal publishing original research, reports, editorials, reviews and commentaries on all aspects of clinical and experimental rheumatology in the clinic and laboratory including the following topics: Pathology, pathophysiology of rheumatological diseases; Investigation, treatment and management

\section{Dovepress}

of rheumatological diseases; Clinical trials and novel pharmacological approaches for the treatment of rheumatological disorders. The manuscript management system is completely online and includes a very quick and fair peer-review system, which is all easy to use. Visit http://www.dovepress.com/testimonials.php to read real quotes from published authors. 